\title{
High-Frequency Afferent Stimulation Induces Long-Term Potentiation of Field Potentials in the Ventral Tegmental Area
}

\author{
Fereshteh S Nugent', Alison R Hwong', Yoko Udaka' and Julie A Kauer*,' \\ 'Department of Molecular Pharmacology, Physiology and Biotechnology, Brown University, Providence, RI, USA
}

\begin{abstract}
Excitatory synapses on dopamine neurons in the VTA can undergo both long-term potentiation and depression. Additionally, druginduced plasticity has been found at VTA synapses, and is proposed to play a role in reward-related learning and addiction by modifying dopamine cell firing. LTP at these synapses is difficult to generate experimentally in that it requires an undisturbed intracellular milieu and is often small in magnitude. Here, we demonstrate the induction of LTP as a property of evoked field potentials within the VTA. Excitatory field potentials were recorded extracellularly from VTA neurons in acute horizontal midbrain slices. Using extracellular and intracellular recording techniques, we found that evoked field potentials originate within the VTA itself and are largely composed of AMPA receptor-mediated EPSPs and action potentials triggered by activation of glutamatergic synapses on both dopamine and GABA neurons. High-frequency afferent stimulation (HFS) induced LTP of the field potential. The induction of this LTP was blocked by application of the NMDAR antagonist, d-APV, prior to HFS. As reported previously, glutamatergic synapses on GABA neurons did not express LTP while those on dopamine neurons did. We conclude that the potentiation of glutamatergic synapses on dopamine neurons is a major contributor to NMDA receptor-dependent LTP of the field potential. Field potential recordings may provide a convenient approach to explore the basic electrophysiological properties of VTA neurons and the development of addiction-related processes in this brain region.

Neuropsychopharmacology (2008) 33, I704-1712; doi: I0. 1038/sj.npp. I 30 I56I; published online 12 September 2007
\end{abstract}

Keywords: field potential; addiction; long-term potentiation; dopamine; high-frequency stimulation; glutamatergic synapses

\section{INTRODUCTION}

The ventral tegmental area (VTA) is essential in processing the reinforcing properties of both natural rewards and addictive drugs (Hyman and Malenka, 2001). Sensitization to drugs of abuse has been proposed as a model underlying aspects of addiction (Hyman et al, 2006), and the VTA is the gateway for initiation of behavioral sensitization and can contribute to relapse (Kauer, 2004).

The VTA contains two types of neurons. Dopamine neurons make up the majority of the population while GABA neurons comprise up to $35 \%$ of the total VTA neurons (Swanson, 1982; Oades and Halliday, 1987; Grace and Onn, 1989; Johnson and North, 1992; Cameron et al, 1997). Both neuron types project to the nucleus accumbens and to the prefrontal cortex, although GABA neurons in the VTA also act locally to inhibit VTA dopamine neurons (Carr and Sesack, 2000a; Svingos et al, 2001). Excitatory afferents to the VTA include direct glutamatergic inputs

*Correspondence: Dr JA Kauer, Department of Molecular Pharmacology, Physiology and Biotechnology, Brown University, I7I Meeting St, BioMed Building, Box GB-4, Providence, RI 02912, USA, Tel: + I 40।8639803, Fax: + I 4018631595, E-mail: julie_kauer@brown.edu Received 22 January 2007; revised 26 June 2007; accepted 28 July 2007 from prefrontal cortex, laterodorsal tegmental nucleus, lateral hypothalamus, and bed nucleus of the stria terminalis (Semba and Fibiger, 1992; Garzon et al, 1999; Carr and Sesack, 2000b; Georges and Aston-Jones, 2001). Stimulation of excitatory afferents in the VTA activates both postsynaptic AMPA receptors and NMDA receptors. GABAergic inputs from the nucleus accumbens and the ventral pallidum, as well as from local GABA neurons inhibit dopamine (and possibly non-dopamine) VTA neurons through $\mathrm{GABA}_{\mathrm{A}}$ and $\mathrm{GABA}_{\mathrm{B}}$ receptors (Johnson and North, 1992; Bonci and Williams, 1996; Fiorillo and Williams, 1998; Bonci and Malenka, 1999).

One possible mechanism underlying the experience- or drug-dependent reorganization of neural circuitry is a change in synaptic strength (ie synaptic plasticity; LTP, and LTD) (Hyman and Malenka, 2001). NMDA receptordependent LTP has been demonstrated at excitatory synapses on midbrain dopamine neurons (Bonci and Malenka, 1999; Overton et al, 1999; Mansvelder and McGehee, 2000; Liu et al, 2005). The demonstration of synaptic plasticity at excitatory synapses in mesolimbic dopaminergic structures, as well as the correlative evidence for changes in glutamate receptor expression and single unit responses to glutamate after in vivo exposure to drugs of abuse, support a role for synaptic plasticity at excitatory 
synapses in the development of addiction (Hyman and Malenka, 2001; Zhang et al, 1997; Carlezon and Nestler, 2002; Thomas and Malenka, 2003).

For decades, extracellular field potential recording has provided a technically easy and relatively uncomplicated method to assess synaptic transmission and plasticity in different regions of the brain. The greatest advantage of extracellular recordings when compared with intracellular recordings is that stable healthy extracellular recordings can be made over several hours. This is desirable for experiments analyzing synaptic plasticity where long-lasting stable changes will be observed. Moreover, field potential recordings provide the possibility of using older animals for drug addiction studies in the VTA. Technical limitations of the in vitro system have thus far limited nearly all studies to very young rats and mice; visualized patch clamp recordings become quite difficult after 3-4 weeks of age. This is particularly relevant as sensitization is less robust and less long lasting at these ages, indicating that examining the cellular physiology of older animals is likely to add information on the persistence of synaptic changes (Kauer, 2004). The great majority of studies on the physiology and pharmacology of the VTA have utilized intracellular microelectrode or patch clamp recordings. Recently, however, extracellular field potential recordings have been made from the VTA in horizontal brain slices (Zheng et al, 2006). Using 6-hydroxydopamine lesions, it was shown that VTA field potentials are largely generated by the postsynaptic responses of dopamine neurons. Here we have taken advantage of this recording method to study LTP induction at excitatory synapses. Before determining whether drugs of abuse elicit any form of plasticity that can be detected in field potentials, it is necessary to address the more straightforward question of whether LTP can be observed as a change in VTA field potentials. Here we report that field potential recordings from VTA slices exhibit LTP. Further studies will be directed toward an assessment of drug-related plasticity at VTA synapses using this electrophysiological technique.

\section{MATERIALS AND METHODS}

\section{Preparation of Brain Slices}

Basic methods were described previously (Jones et al, 2000). Sprague-Dawley rats (17-62 days old) were anesthetized using halothane and quickly decapitated. The brain was rapidly removed into ice-cold artificial cerebrospinal fluid (ACSF) containing (in mM): $126 \mathrm{NaCl}, 21.4 \mathrm{NaHCO}_{3}, 2.5$ $\mathrm{KCl}, 1.2 \mathrm{NaH}_{2} \mathrm{PO}_{4}, 2.4 \mathrm{CaCl}_{2}, 1.2 \mathrm{MgSO}_{4}, 11.1$ dextrose, with either $75 \mathrm{mM}$ sucrose or 0.4 ascorbic acid added. These solutions were saturated with $95 \% \mathrm{O}_{2}$ and $5 \% \mathrm{CO}_{2}$ ( $\mathrm{pH} 7.4$ ). Horizontal midbrain slices $(400 \mu \mathrm{m}$ thick) were prepared, stored for at least $1 \mathrm{~h}$ at room temperature in either sucrosecontaining ACSF or at $35^{\circ} \mathrm{C}$ in ascorbic acid-containing ACSF, and transferred to an interface recording chamber where the slice rested on a strip of filter paper saturated with ACSF $\left(28-32^{\circ} \mathrm{C}\right)$, with warmed, humidified $\mathrm{CO}_{2} / \mathrm{O}_{2}$ blown over the surface. To record field potentials from midbrain slices prepared from 55 to 62-day-old rats, we cut thinner slices $(300 \mu \mathrm{M})$ to improve the visibility of VTA landmarks in this more myelinated tissue.

\section{Electrophysiological Recording}

Midbrain slices were continuously perfused with ACSF (without sucrose or ascorbic acid) at $28-32^{\circ} \mathrm{C}$ at a flow rate of $0.5 \mathrm{ml} / \mathrm{min}$. In some experiments $100 \mu \mathrm{M}$ picrotoxin was added to the ACSF to block $\mathrm{GABA}_{\mathrm{A}}$ receptors (see below). Extracellular recordings were made from VTA neurons using broken back microelectrodes with a tip resistance of $\sim 1 \mathrm{M} \Omega$ and filled with $2 \mathrm{M} \mathrm{NaCl}$. Sharp microelectrodes for intracellular recordings had resistances between 100 and $200 \mathrm{M} \Omega$ and were filled with $2 \mathrm{M} \mathrm{KCl}$ or $2 \mathrm{M} \mathrm{CsMeSO}_{4}$ in some experiments. For intracellular recordings, an $I_{\mathrm{h}}$ current was used to distinguish dopamine from GABA neurons. If the $I_{\mathrm{h}}$ current during a step from -50 to $-100 \mathrm{mV}$ was present, the neuron was considered a dopamine neuron; if not, the cell was classified as a GABA neuron. While the absence of $I_{\mathrm{h}}$ reliably predicts that a VTA neuron is non-dopaminergic, $I_{\mathrm{h}}$ is also present in a group of VTA neurons, which are not dopaminergic (Margolis et al, 2006).

Field potentials or EPSPs were stimulated at $0.1 \mathrm{~Hz}$ (100 $\mu$ s pulse) using a bipolar stainless-steel stimulating electrode placed $200-500 \mu \mathrm{m}$ rostral to the recording site in the VTA. LTP was induced by stimulating afferents at $100 \mathrm{~Hz}$ for $1 \mathrm{~s}$; this train was repeated twice $20 \mathrm{~s}$ apart (highfrequency stimulation (HFS)). In intracellular recording experiments, LTP induction was attempted in both dopamine and GABA neurons using the same protocol (HFS) during direct depolarizing current injection $(0.4-4 \mathrm{nA}$ during each $1 \mathrm{~s}$ train). In all LTP experiments, picrotoxin $(100 \mu \mathrm{M})$ was included in the ACSF to facilitate NMDA receptor-dependent LTP.

\section{Analysis}

Results are expressed as mean \pm SEM. Significant changes between experimental conditions were determined using a Student's $t$-test with significance level of $p<0.05$. Levels of LTP are reported as averaged EPSP or field potential amplitudes for a $5 \mathrm{~min}$ time period just before the LTP induction compared with averaged EPSP or field potential amplitudes during the $10 \mathrm{~min}$ period from 30 to $40 \mathrm{~min}$ after HFS.

\section{Drug Application}

The following drugs were used in this study: the $\mathrm{GABA}_{\mathrm{A}}$ receptor antagonist, picrotoxin $(100 \mu \mathrm{M})$; the $\mathrm{GABA}_{\mathrm{B}}$ agonist, baclofen $(30 \mu \mathrm{M})$; the AMPA receptor antagonist, DNQX $(10 \mu \mathrm{M})$; the NMDA receptor antagonist, D-APV $(50 \mu \mathrm{M})$; and the sodium channel blocker, tetrodotoxin (TTX, $1 \mu \mathrm{M})$. All drugs were added directly to the ACSF perfusing the slice chamber at known concentrations. DAPV was added for at least 15 min before HFS. Drug effects were assessed by averaging field potential amplitudes for 5 min during the peak response and comparing this value with $5 \mathrm{~min}$ of averaged data before drug application. In experiments reported in Figure 1, DNQX was focally applied through a puffer pipette positioned close to the recording electrode and above the slice. The solution contained fast green so that the pressure-ejected solution clearly marked the slice. Only experiments in which the drug remained 
a
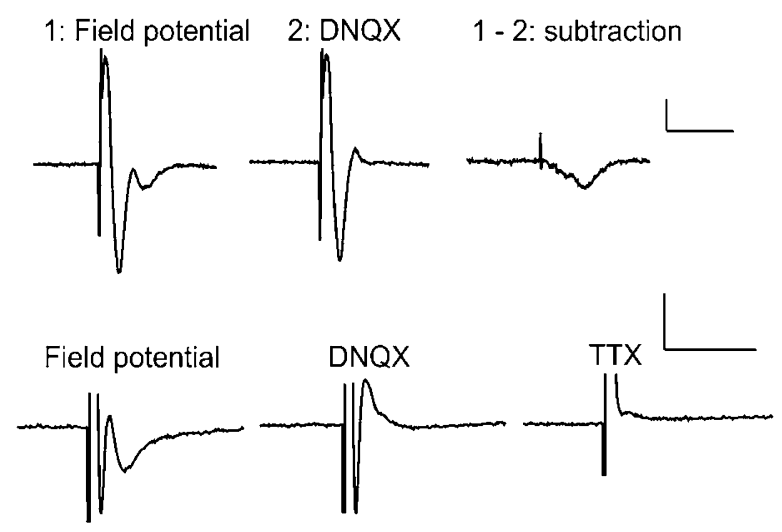

b
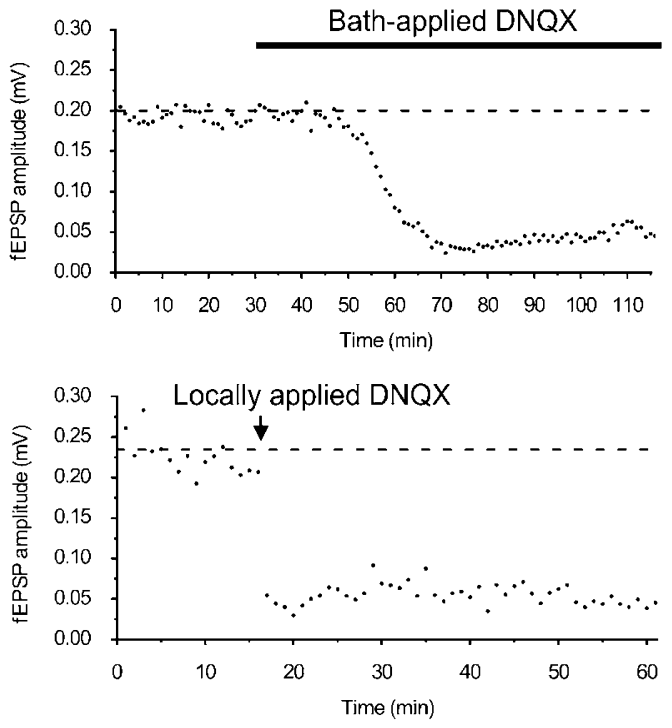

C

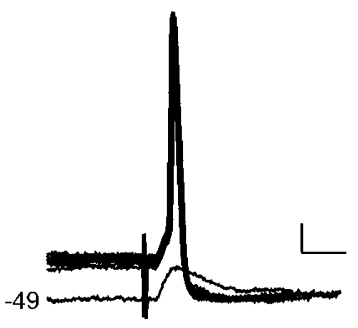

d

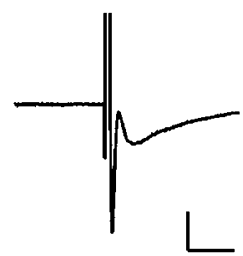

Figure I VTA field potentials are mediated by AMPAR-mediated EPSPS and postsynaptic action potentials. (a) Extracellularly recorded field potentials obtained from a VTA slice. Upper panel: Local application of I mM DNQX restricted within the VTA abolished the late synaptic component of the field potential (sample traces in first row). Digital subtraction of the field potential with and without DNQX reveals the AMPAR-mediated component of the field potential. Lower panel: in a second slice, bath application of $10 \mu \mathrm{M}$ DNQX also abolished the late synaptic component of field potentials; application of the $\mathrm{Na}^{+}$channel blocker, TTX $(\mid \mu M)$, completely eliminated the fast initial fiber volley component of field potentials (sample traces in second row). For each example, 10 consecutive potentials are averaged. Calibration: $0.25 \mathrm{mV}$, 10 ms. (b) Bath application of $10 \mu \mathrm{M}$ DNQX (top panel) or local application of I mM DNQX (bottom panel) blocked the synaptic component of the field potential. (c) Intracellular recordings from VTA neurons revealed that these neurons had resting potentials near threshold, and that synaptic stimulation often elicited an action potential ( 10 superimposed sweeps of evoked responses from one individual neuron, using a stimulus strength comparable to those used in field potential experiments). Calibration: $5 \mathrm{mV}, 10 \mathrm{~ms}$. (d) Extracellularly recorded field potential from the VTA in a brain slice from a 60-day-old rat. Ten consecutive potentials are averaged. Calibration: $0.25 \mathrm{mV}, 10 \mathrm{~ms}$. within the boundaries of the VTA were reported. Salts and all other drugs were obtained from Sigma-Research Biochemicals International.

\section{RESULTS}

\section{Characterization of Evoked Field Potentials in the VTA}

Extracellular field potentials were both recorded and reliably evoked by electrical stimulation within the VTA (see also Zheng et al, 2006). We used identifiable structures (eg the medial terminal nucleus of the accessory optic tract (MT) and substantia nigra) as landmarks in these slices to position the electrodes inside the VTA, generally medial and slightly caudal to the MT (Paxinos and Watson, 1986). We also recorded field potentials using a submerged chamber and found that field potentials can be recorded in this chamber type as well. A major advantage of the interface chamber is that fluid shunting is minimized, which increases the size of the recorded extracellular field potential. In the interface chamber, these potentials in the VTA can be nearly a millivolt in amplitude, whereas in the submerged chamber, they are usually much smaller $(<200 \mu \mathrm{V})$.

The evoked local field potential has two components: the initial fast component (the action potential or fiber volley component) and the later synaptic component, which we will refer to as the field potential (Figure 1a). The synaptic component of the field potential is completely eliminated by bath application of the AMPAR antagonist, DNQX $(10 \mu \mathrm{M}$, Figure 1a and b). Since field potentials can be recorded at some distance from current sources, we also applied DNQX locally around the recording site. We found that even when DNQX application was restricted to the VTA, the field potential was entirely blocked $(n=3$; Figure $1 \mathrm{a}$ and $\mathrm{b}$ ). These data strongly suggest that the field potential depends upon activation of AMPA receptors within the VTA. The fast component was unaffected by DNQX application, but was abolished by bath application of the sodium channel blocker, tetrodotoxin (TTX, $1 \mu \mathrm{M}$ ) (Figure 1a). This finding suggests that this component represents the fiber volley generated by antidromic and orthodromic action potentials originating at the stimulation site.

The synaptic component of the field potential was largely blocked by DNQX. This may have resulted from the combination of two effects - block of both the AMPARmediated EPSP and EPSP-triggered action potentials. Intracellular recordings showed that under our recording/ stimulating conditions, many individual neurons fire action potentials in response to the stimulus (Figure 1c). Thus, the field potential we record most likely represents combined EPSPs and EPSP-driven action potentials.

To determine whether it is possible to record field potentials from older animals, we next tried recording from midbrain slices prepared from 55 to 62 -day-old rats. We were able to stimulate extracellularly recorded field potentials similar to those seen in slices from younger animals, and that ranged from 100 to $500 \mu \mathrm{V}$ (Figure 1d, $n=4)$. Picrotoxin $(100 \mu \mathrm{M})$ reliably increased the field potential amplitude $(n=3)$. Slices from these animals are far less translucent due to increased myelination, and we 


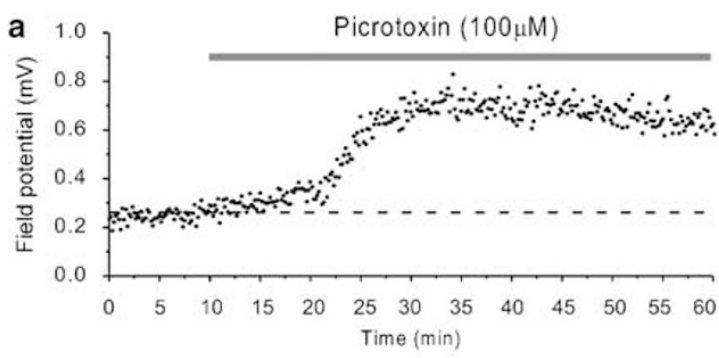

b
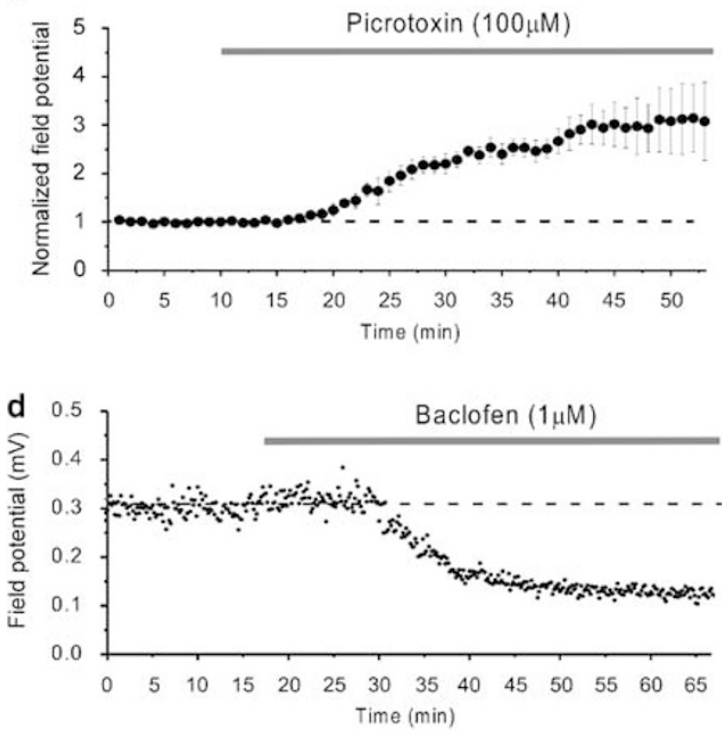

C

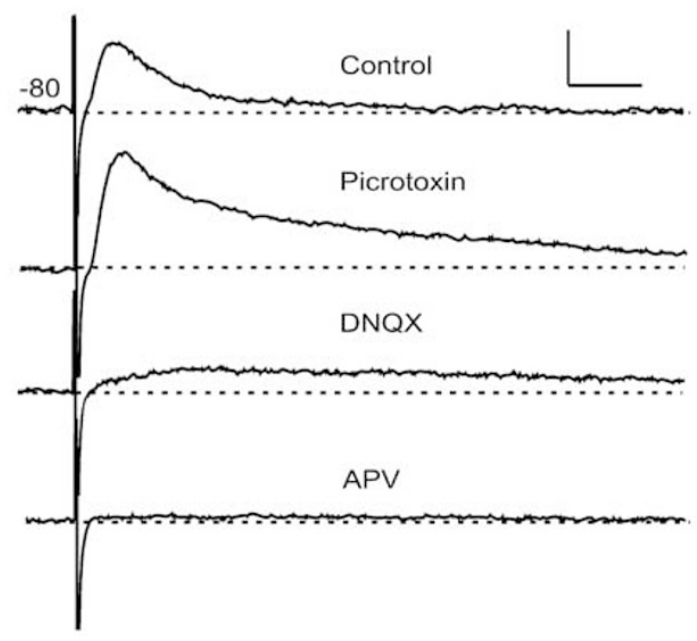

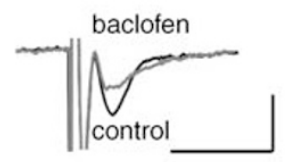

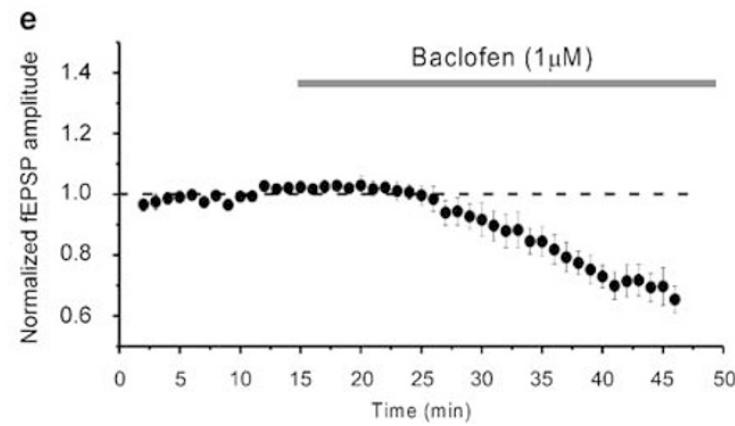

Figure 2 Extracellular field potentials consist of both excitatory and inhibitory synaptic components. (a) A single experiment with the GABA $A_{A}$ antagonist, picrotoxin (I00 $\mathrm{M}$ ). Inset: 10 averaged field potentials before (black) and $25 \mathrm{~min}$ after drug application (gray). Calibration: $0.25 \mathrm{mV}, 10 \mathrm{~ms}$. (b) Average of four experiments with picrotoxin $(100 \mu \mathrm{M})$. Picrotoxin strongly enhanced the amplitude of field potentials recorded in the VTA (252 $\pm 3 \%$ of predrug values). (c) Sample synaptic potentials recorded with an intracellular sharp microelectrode from a dopamine neuron held at $-80 \mathrm{mV}$. Synaptic potentials have components mediated by GABARs and glutamate receptors. Top trace: control PSP. Second trace: picrotoxin blocked GABA $\mathrm{A}_{\mathrm{A}}$-mediated IPSP, leaving AMPAR and NMDAR-mediated synaptic potentials (EPSPs). Third trace: $10 \mu M$ DNQX blocked much of the remaining synaptic potential. Bottom trace: the remaining postsynaptic potential was abolished by d-APV $(50 \mu \mathrm{M})$, indicating that it was NMDAR-dependent. Calibration: $5 \mathrm{mV}$, $10 \mathrm{~ms}$. Baclofen depresses the amplitude of field potentials. (d) A single experiment showing that the $G_{A B A} R$ agonist, baclofen ( I $\mu M$ ) reduces the VTA field potential. Inset: averaged field potentials before (black) and $25 \mathrm{~min}$ after drug application (gray). Calibration: $0.25 \mathrm{mV}, 10 \mathrm{~ms}$. (e) Average of five experiments with baclofen (69 \pm I\% of predrug values).

thus cut thinner slices $(300 \mu \mathrm{M})$ to improve the visibility of VTA landmarks. Although we have not further characterized the extracellularly recorded field potentials in mature rats, our results indicate that this recording method has the potential for use at many ages.

We expected that evoked field potentials recorded in picrotoxin-free ACSF might contain a GABAergic component, representing current flow through $\mathrm{GABA}_{\mathrm{A}}$ receptors at inhibitory synapses. These inhibitory synaptic responses may occur at a similar latency to the excitatory synaptic potentials, potentially reducing the actual amplitude of the field potentials. As predicted, bath application of the $\mathrm{GABA}_{\mathrm{A}} \mathrm{R}$ antagonist, picrotoxin $(100 \mu \mathrm{M})$, dramatically increased the amplitude of the evoked field potential (Figure 2a and $\mathrm{b}$ ). To test whether the enhancing effect of picrotoxin on the size of the field potential results from blockade of the evoked $\mathrm{GABA}_{\mathrm{A}}$ IPSPs, we made intracellular recordings from VTA neurons with $\mathrm{CsMeSO}_{4}$-filled electrodes while holding the cells at $-80 \mathrm{mV}$. In agreement with previous findings (Johnson and North, 1992), focal stimulation within the VTA evoked a mixed synaptic potential. Bath application of picrotoxin blocked the IPSP, which increased the amplitude of the depolarizing excitatory potential (EPSP). Even at this quite hyperpolarized potential, the EPSP is mediated by both AMPA and NMDA receptor-mediated potentials (Figure 2c; see also Johnson and North, 1992). These data suggest that the enhancing effect of picrotoxin on field potentials is due to the elimination of overlapping IPSPs. The complete block of the field potential by DNQX in Figure 1 also suggests that the $\mathrm{GABA}_{\mathrm{A}} \mathrm{R}$-mediated IPSP does not contribute to the extracellularly recorded field potential, or perhaps that most of the IPSP is driven by stimulus-activated glutamatergic afferents onto local GABA neurons. Since picrotoxin blocks GABAergic inhibition, which controls the membrane potential of neurons, picrotoxin most likely facilitates the excitability of VTA neurons, promoting an increase in action potential firing. 
In addition to AMPA, NMDA, and $\mathrm{GABA}_{\mathrm{A}}$ receptormediated synaptic potentials, $\mathrm{GABA}_{\mathrm{B}}$ receptors contribute to a late hyperpolarizing synaptic potential in dopamine neurons (Johnson and North, 1992; Cameron and Williams, 1993; Shoji et al, 1999). We tested the effect of baclofen, the $\mathrm{GABA}_{\mathrm{B}} \mathrm{R}$ agonist on field potential amplitude. Baclofen caused a $30 \%$ depression in the field potential amplitude (Figure 2d-e). However, the effect of baclofen on the field potential could involve two distinct populations of $\mathrm{GABA}_{\mathrm{B}}$ receptors, located not only on postsynaptic cells but also on presynaptic glutamatergic terminals. $\mathrm{GABA}_{\mathrm{B}}$ receptors on dopamine neurons will hyperpolarize these cells, thus reducing their likelihood of firing action potentials (and therefore reducing field potential amplitude) (Mueller and Brodie, 1989); $\mathrm{GABA}_{\mathrm{B}}$ receptors have been suggested to be present only on glutamatergic afferents on GABA neurons but not dopamine neurons (Bonci and Malenka,
1999). Thus, a decrease in the field potential with baclofen could also reflect a selective depression of EPSPs on GABA cells.

\section{High-Frequency Afferent Stimulation can Induce NMDA Receptor-Dependent LTP of Field Potential}

Previously, synaptic plasticity of glutamatergic inputs onto VTA neurons has been analyzed using perforated patch clamp recordings (Bonci and Malenka, 1999) or using sharp microelectrodes (Overton et al, 1999). We recorded intracellularly using sharp microelectrodes and confirmed these previous findings. LTP induction was attempted in both dopamine and GABA neurons using HFS during direct depolarizing current injection. We found that glutamatergic synapses on dopamine neurons expressed LTP but synapses on GABA cells did not (Figure $3 \mathrm{a}-\mathrm{c}$ ).
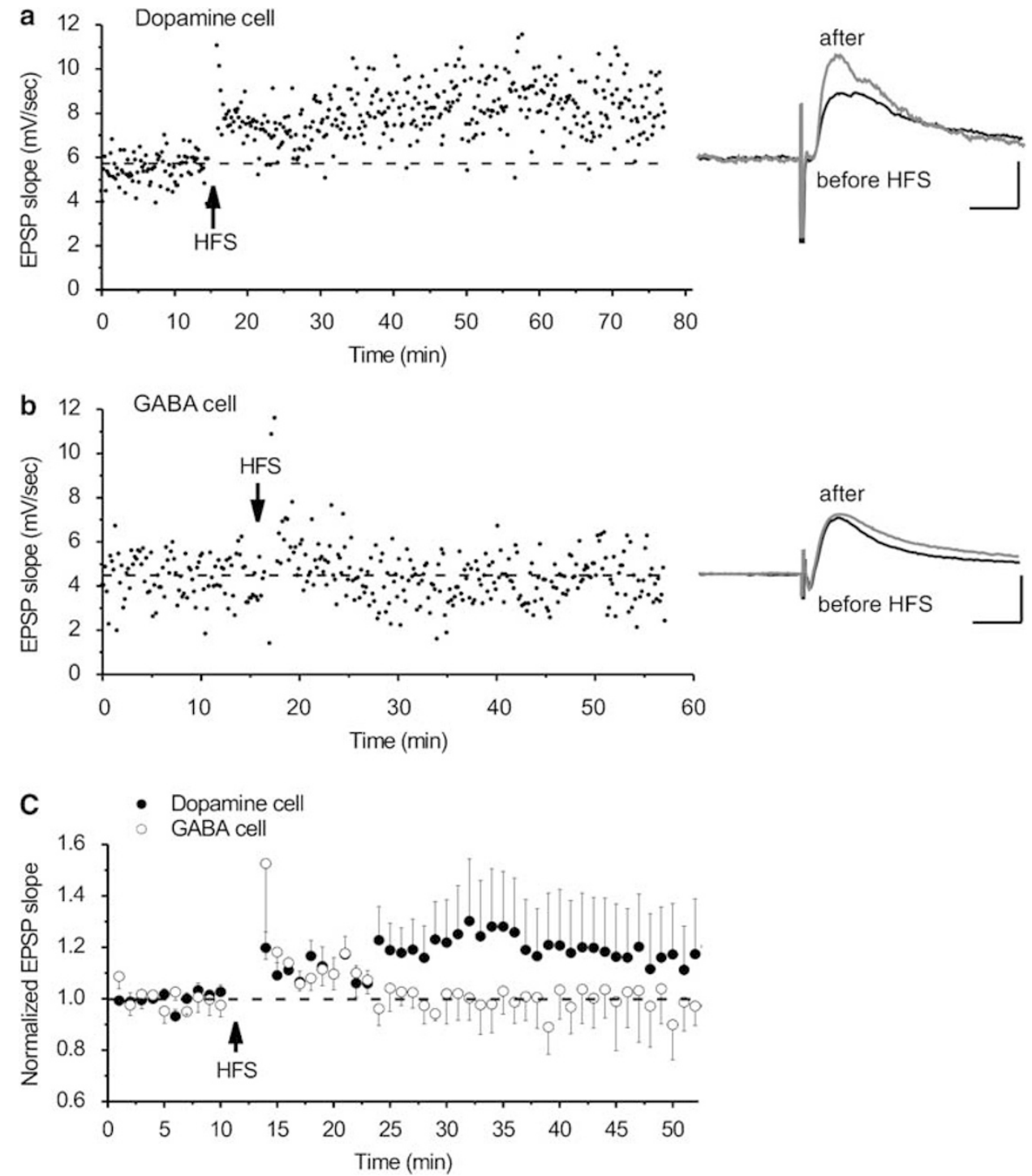

Figure 3 Excitatory synapses on dopamine cells express LTP while those on GABA cells do not. (a) Intracellular recording from a dopamine neuron exhibiting LTP after HFS (arrow). Inset: averaged EPSPs before (black) and 25 min after HFS (gray). Calibration: $5 \mathrm{mV}, 10 \mathrm{~ms}$. (b) Intracellular recording from a GABA neuron that did not express LTP after HFS. Inset: averaged EPSPs before (black) and 25 min after HFS (gray). Calibration: $5 \mathrm{mV}$, I 0 ms. (c) Averaged experiments from dopamine and GABA neurons in response to HFS (dopamine neurons, filled symbols: $127 \pm 2.4 \%$ of pre-HFS values, $p<0.002, n=10$; GABA neurons, open symbols: $97 \pm 2.5 \%$ of pre-HFS values, $p=0.587, n=4)$. 

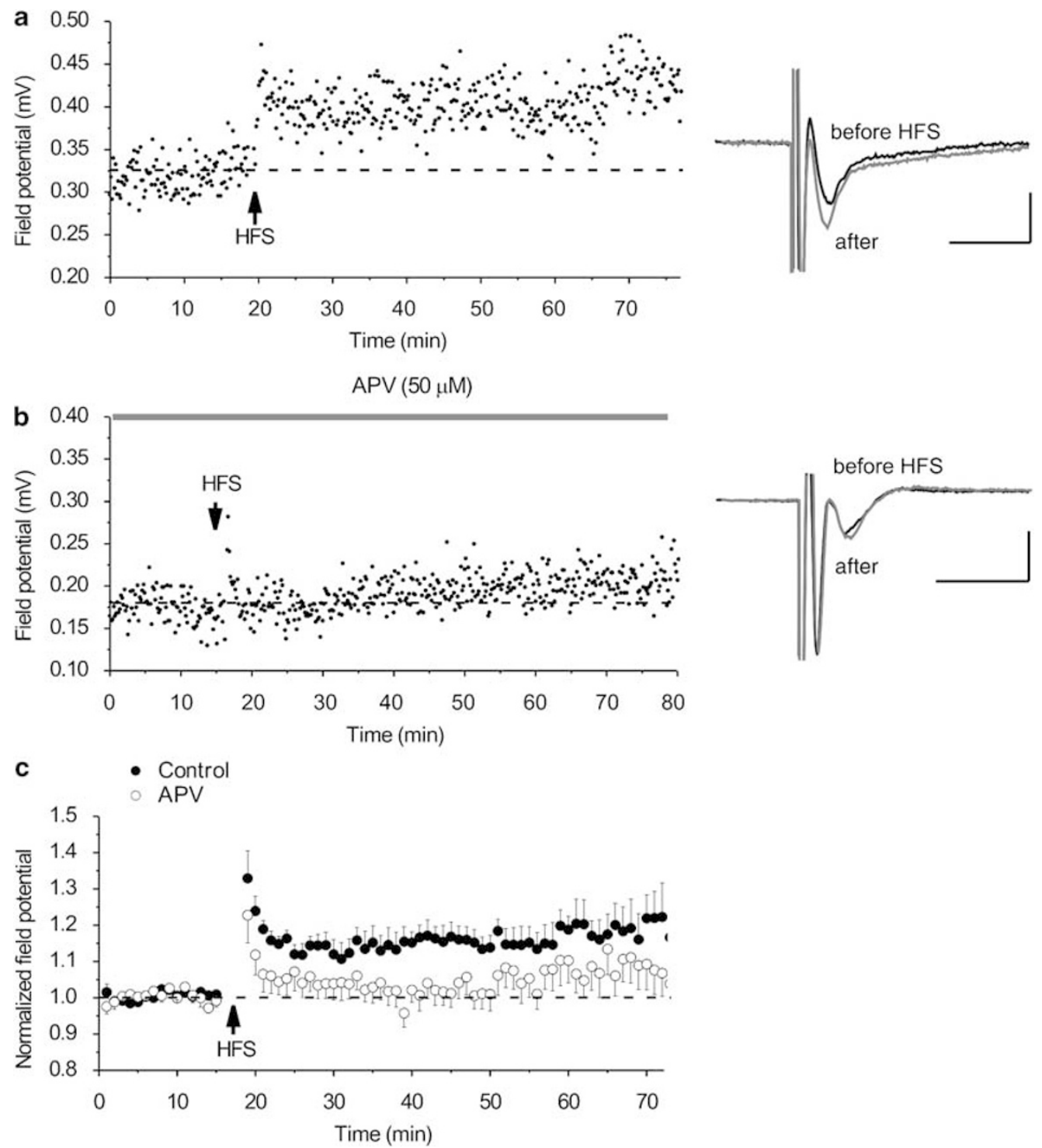

Figure 4 Induction of NMDAR-dependent LTP of VTA field potentials by HFS. (a) Single experiment exhibiting LTP of the field potential by HFS. Inset: averaged field potentials before (black) and $25 \mathrm{~min}$ after HFS (gray). Calibration: $0.25 \mathrm{mV}$, $10 \mathrm{~ms}$. (b) Single experiment exhibiting the block of field potential LTP by d-APV $(50 \mu \mathrm{M})$. Inset: averaged field potentials before (black) and 25 min after HFS (gray). Calibration: $0.25 \mathrm{mV}, 10 \mathrm{~ms}$. (c) Averaged experiments with and without d-APV in response to HFS. d-APV $(50 \mu \mathrm{M}$ ) was present for at least 15 min before HFS (control LTP, filled symbols: I I $6 \pm 0.67$ of pre-HFS values, $p<0.00002, n=15$; APV experiments, open symbols: $101 \pm 1.3$ of pre-HFS values, $p=0.168, n=9$ ).

Owing to the relative ease of making field potential recordings, we wanted to ascertain whether we could observe LTP at excitatory synapses using field potential recordings. HFS of glutamatergic afferents induced LTP. This is the first demonstration of LTP of field potentials of the VTA. In these experiments we observed LTP in 7 of 15 slices (Figure $4 \mathrm{a}$ and $\mathrm{c}$ ). Given that our intracellular recordings showed no LTP of synapses on GABA neurons, these findings suggest that LTP of the field potential represents the potentiated glutamatergic synapses on dopamine neurons. If the LTP of the field potential is due to LTP of glutamatergic synapses on dopamine neurons, then the underlying molecular mechanism for induction of this LTP should be the same. LTP triggered by synaptic stimulation in slices as well as that triggered by drugs of abuse in vivo is blocked by NMDAR antagonists (Bonci and Malenka, 1999; Overton et al, 1999; Ungless et al, 2001). We therefore tested whether the NMDA receptor blocker, d-APV, prevented LTP of the field potential. As expected, d-APV $(50 \mu \mathrm{M})$ blocked the induction of field potential LTP (Figure $4 \mathrm{~b}$ and $c$ ) suggesting that the induction of field potential LTP is also NMDA receptor-dependent. These data further support the idea that the LTP of the field potential represents plasticity that occurs at synapses on dopamine neurons. Although both cell types contribute to field potentials, the different basic properties of excitatory synapses onto these neurons can be detected in field potentials and this will provide the possibility of studying plasticity of synapses onto individual neuronal populations. 


\section{DISCUSSION}

In the present study, we have demonstrated that excitatory field potentials can be evoked in the VTA in brain slices. We report that the field potential is comprised of both synaptic potentials and postsynaptic action potentials. Furthermore, NMDA receptor-dependent LTP of the field potential can be induced in the VTA by high-frequency afferent stimulation. This is the first demonstration of LTP of field potentials in the VTA. The ability to record LTP using this relatively simple electrophysiological approach will provide a useful tool for assessing drug-related plasticity.

\section{VTA Field Potentials are Comprised of AMPA Receptor-Mediated EPSPs and Action Potentials in Local Neurons}

Consistent with the recent report of Zheng et al (2006), VTA field potentials could be consistently evoked in the present study. The diffuse distribution of cells and their dendritic arborizations in the VTA, unlike that of highly laminar structures such as the hippocampus, gives rise to a much smaller evoked field potential $(0.1-1 \mathrm{mV})$. The synaptic component of the field potential is completely eliminated by the local application of DNQX, suggesting that the field potential we record indeed arises from synaptic activity in the VTA itself. Intracellular recording experiments revealed that the recorded field potentials are most likely a mix of AMPA receptor-mediated synaptic potentials and postsynaptic action potentials. Blockade of AMPA receptormediated EPSPs by DNQX blocks the generation of postsynaptic action potentials, as it prevents postsynaptic neurons from reaching their threshold.

Bath application of picrotoxin considerably increased the amplitude of evoked field potentials, indicating that evoked GABAergic inhibition masks part of the excitatory field potential. Two mechanisms are expected to contribute to this effect. First, the $\mathrm{GABA}_{\mathrm{A}} \mathrm{R}$-mediated IPSPs evoked by local electrical stimulation will hyperpolarize the postsynaptic neuron, overlapping in time, and canceling some of the depolarization elicited by simultaneously evoked EPSPs (Johnson and North, 1992). When picrotoxin removes the IPSP, the EPSP will provide more effective depolarization. Second, removal of $\mathrm{GABA}_{\mathrm{A}}$ - mediated inhibition will increase the likelihood of action potential generation, which we believe contributes significantly to our recorded field potential.

\section{Dopamine Neurons are Primarily Responsible for Generating VTA Field Potentials}

We also tested the effect on field potential amplitude of baclofen, a $\mathrm{GABA}_{\mathrm{B}}$ agonist. Baclofen produces a robust inhibition of firing and a pronounced hyperpolarization of neurons of the VTA (Mueller and Brodie, 1989). We found that baclofen reduced the field potential amplitude by $30 \%$, probably due in part to this postsynaptic hyperpolarization. Additionally, however, excitatory synapses on dopamine neurons are reportedly to be minimally affected by baclofen, while synapses on GABA neurons are significantly depressed by baclofen. These data suggest that part of the reduction of the field potential we recorded in baclofen may be caused by blocking excitatory synapses onto GABA neurons. This raises an interesting question regarding the relative contribution of dopamine $v s$ GABA cells in generating the local field responses. Excitatory synaptic potentials and action potentials can be evoked in both cell types by focal stimulation inside the VTA. The majority of neurons in the VTA are dopamine neurons; Zheng et al (2006) have shown that elimination of VTA dopamine cells by neonatal 6-OHDA administration reduced more than $50 \%$ of the evoked field potentials. Taken together, these findings suggest that excitatory synaptic potentials and action potentials in dopamine neurons contribute more to the evoked field potential than those on local GABAergic neurons.

\section{NMDAR-Dependent LTP of Field Potentials Presents a Simpler Model to Study Effects of Addictive Drugs}

An exciting question in the drug addiction field concerns the functional significance of drug-induced plasticity at VTA synapses. All addictive drugs increase the levels of synaptic dopamine released at nerve terminals within the NAc (Di Chiara and Imperato, 1988; Koob, 1992; Nestler, 1992). Glutamate controls many aspects of dopamine cell function, including midbrain dopamine cell firing and dopamine release. Thus, is drug-induced release of dopamine within the NAc the functional consequence of LTP at VTA glutamatergic synapses? Several lines of evidence suggest that glutamatergic synaptic plasticity in the VTA rapidly induced by exposure to drugs of abuse may in fact change the firing patterns of dopamine neurons and thus modify dopamine release (Kauer, 2004; Jones and Bonci, 2005).

The development of behavioral sensitization involves an LTP-like process in the VTA. In vivo administration of drugs of abuse with different molecular mechanisms of action as well as acute stress do, in fact, elicit LTP at excitatory synapses on VTA dopamine neurons (Bonci and Malenka, 1999; Ungless et al, 2001; Saal et al, 2003). The response to cocaine and stress have also been shown to require NMDAR activation (Shors and Servatius, 1995; Li et al, 1999; Thomas et al, 2001; Borgland et al, 2004). Our results suggest that extracellular field potential recording represents a viable alternative to studying these key questions using a technically straightforward approach. Furthermore, extracellular field potentials recorded in vivo from the VTA are also possible, and may make it possible to link more directly in vivo and in vitro findings (Peters et al, 2004; Dommett et al, 2006).

In the present study, we have provided the first demonstration of LTP of excitatory field potentials recorded from VTA neurons using high-frequency stimulation of glutamatergic afferents. While excitatory synapses on dopamine cells undergo LTP, we confirmed that excitatory synapses on GABA cells do not (Bonci and Malenka, 1999). The field potential LTP is NMDA receptor-dependent. If pretreatment with in vivo drugs of abuse induces LTP of field potentials, then the in vitro induction of field potential LTP is expected to be reduced in slices prepared from these animals. Given the technical difficulty of obtaining LTP of excitatory synapses in the VTA using intracellular recording methods, it is worthwhile to pursue an uncomplicated 
methodology (ie the field potential recording procedure) to monitor drug-induced plasticity.

\section{ACKNOWLEDGEMENTS}

This work was supported by a NARSAD award and NIH Grant DA11289. We are grateful to Drs Helen Gibson and Jason Niehaus for helpful discussions and to Jeannette Downing-Park for technical assistance.

\section{DISCLOSURE/CONFLICT OF INTEREST}

The author(s) declare that, except for income received from my primary employer, no financial support or compensation has been received from any individual or corporate entity over the past 3 years for research or professional service and there are no personal financial holdings that could be perceived as constituting a potential conflict of interest.

\section{REFERENCES}

Bonci A, Malenka RC (1999). Properties and plasticity of excitatory synapses on dopaminergic and GABAergic cells in the ventral tegmental area. J Neurosci 19: 3723-3730.

Bonci A, Williams JT (1996). A common mechanism mediates long-term changes in synaptic transmission after chronic cocaine and morphine. Neuron 16: 631-639.

Borgland SL, Malenka RC, Bonci A (2004). Acute and chronic cocaine-induced potentiation of synaptic strength in the ventral tegmental area: electrophysiological and behavioral correlates in individual rats. J Neurosci 24: 7482-7490.

Cameron DL, Wessendorf MW, Williams JT (1997). A subset of ventral tegmental area neurons is inhibited by dopamine, 5-hydroxytryptamine and opioids. Neuroscience 77: 155-166.

Cameron DL, Williams JT (1993). Dopamine D1 receptors facilitate transmitter release. Nature 366: 344-347.

Carlezon Jr WA, Nestler EJ (2002). Elevated levels of GluR1 in the midbrain: a trigger for sensitization to drugs of abuse? Trends Neurosci 25: 610-615.

Carr DB, Sesack SR (2000a). GABA-containing neurons in the rat ventral tegmental area project to the prefrontal cortex. Synapse 38: 114-123.

Carr DB, Sesack SR (2000b). Projections from the rat prefrontal cortex to the ventral tegmental area: target specificity in the synaptic associations with mesoaccumbens and mesocortical neurons. J Neurosci 20: 3864-3873.

Di Chiara G, Imperato A (1988). Drugs abused by humans preferentially increase synaptic dopamine concentrations in the mesolimbic system of freely moving rats. Proc Natl Acad Sci USA 85: 5274-5278.

Dommett EJ, Simpson J, Clark D, Overton PG (2006). Identification of an excitatory amino acid-mediated component of the ventral tegmental area local field potential response to medial prefrontal cortex stimulation: effect of acute d-amphetamine. J Neural Transm 114: 161-172.

Faleiro LJ, Jones S, Kauer JA (2004). Rapid synaptic plasticity of glutamatergic synapses on dopamine neurons in the ventral tegmental area in response to acute amphetamine injection. Neuropsychopharmacology 29: 2115-2125.

Fiorillo CD, Williams JT (1998). Glutamate mediates an inhibitory postsynaptic potential in dopamine neurons. Nature 394: 78-82. Garzon M, Vaughan RA, Uhl GR, Kuhar MJ, Pickel VM (1999). Cholinergic axon terminals in the ventral tegmental area target a subpopulation of neurons expressing low levels of the dopamine transporter. J Comp Neurol 410: 197-210.

Georges F, Aston-Jones G (2001). Potent regulation of midbrain dopamine neurons by the bed nucleus of the stria terminalis. J Neurosci 21: RC160.

Grace AA, Onn SP (1989). Morphology and electrophysiological properties of immunocytochemically identified rat dopamine neurons recorded in vitro. J Neurosci 9: 3463-3481.

Hyman SE, Malenka RC (2001). Addiction and the brain: the neurobiology of compulsion and its persistence. Nat Rev Neurosci 2: 695-703.

Hyman SE, Malenka RC, Nestler EJ (2006). Neural mechanisms of addiction: the role of reward-related learning and memory. Annu Rev Neurosci 29: 565-598.

Johnson SW, North RA (1992). Two types of neurone in the rat ventral tegmental area and their synaptic inputs. J Physiol 450: $455-468$.

Jones S, Bonci A (2005). Synaptic plasticity and drug addiction. Curr Opin Pharmacol 5: 20-25.

Jones S, Kornblum JL, Kauer JA (2000). Amphetamine blocks long-term synaptic depression in the ventral tegmental area. J Neurosci 20: 5575-5580.

Kauer JA (2004). Learning mechanisms in addiction: synaptic plasticity in the ventral tegmental area as a result of exposure to drugs of abuse. Annu Rev Physiol 66: 447-475.

Koob GF (1992). Neural mechanisms of drug reinforcement. Ann N Y Acad Sci 654: 171-191.

Li Y, Hu XT, Berney TG, Vartanian AJ, Stine CD, Wolf ME et al (1999). Both glutamate receptor antagonists and prefrontal cortex lesions prevent induction of cocaine sensitization and associated neuroadaptations. Synapse 34: 169-180.

Liu QS, Pu L, Poo MM (2005). Repeated cocaine exposure in vivo facilitates LTP induction in midbrain dopamine neurons. Nature 437: 1027-1031.

Mansvelder HD, McGehee DS (2000). Long-term potentiation of excitatory inputs to brain reward areas by nicotine. Neuron 27: 349-357.

Margolis EB, Lock H, Hjelmstad GO, Fields HL (2006). The ventral tegmental area revisited: is there an electrophysiological marker for dopaminergic neurons? J Physiol 577: 907-924.

Mueller AL, Brodie MS (1989). Intracellular recording from putative dopamine-containing neurons in the ventral tegmental area of Tsai in a brain slice preparation. J Neurosci Methods 28: $15-22$.

Nestler EJ (1992). Molecular mechanisms of drug addiction. J Neurosci 12: 2439-2450.

Oades RD, Halliday GM (1987). Ventral tegmental (A10) system: neurobiology. 1. Anatomy and connectivity. Brain Res 434: 117-165.

Overton PG, Richards CD, Berry MS, Clark D (1999). Long-term potentiation at excitatory amino acid synapses on midbrain dopamine neurons. Neuroreport 10: 221-226.

Paxinos G, Watson C (1986). The Rat Brain in Stereotaxic Coordinates, 4th edn. Academic press: San Diego, CA, USA.

Peters Y, Barnhardt NE, O’Donnell P (2004). Prefrontal cortical up states are synchronized with ventral tegmental area activity. Synapse 52: 143-152.

Saal D, Dong Y, Bonci A, Malenka RC (2003). Drugs of abuse and stress trigger a common synaptic adaptation in dopamine neurons. Neuron 37: 577-582.

Semba K, Fibiger HC (1992). Afferent connections of the laterodorsal and the pedunculopontine tegmental nuclei in the rat: a retro- and antero-grade transport and immunohistochemical study. J Comp Neurol 323: 387-410.

Shoji Y, Delfs J, Williams JT (1999). Presynaptic inhibition of GABA(B)-mediated synaptic potentials in the ventral tegmental area during morphine withdrawal. J Neurosci 19: 2347-2355. 
Shors TJ, Servatius RJ (1995). Stress-induced sensitization and facilitated learning require NMDA receptor activation. Neuroreport 6: 677-680.

Svingos AL, Garzon M, Colago EE, Pickel VM (2001). Mu-opioid receptors in the ventral tegmental area are targeted to presynaptically and directly modulate mesocortical projection neurons. Synapse 41: 221-229.

Swanson LW (1982). The projections of the ventral tegmental area and adjacent regions: a combined fluorescent retrograde tracer and immunofluorescence study in the rat. Brain Res Bull 9: 321-353.

Thomas MJ, Beurrier C, Bonci A, Malenka RC (2001). Longterm depression in the nucleus accumbens: a neural correlate of behavioral sensitization to cocaine. Nat Neurosci 4: 1217-1223.
Thomas MJ, Malenka RC (2003). Synaptic plasticity in the mesolimbic dopamine system. Philos Trans $R$ Soc Lond B Biol Sci 358: 815-819.

Ungless MA, Whistler JL, Malenka RC, Bonci A (2001). Single cocaine exposure in vivo induces long-term potentiation in dopamine neurons. Nature 411: 583-587.

Zhang XF, Hu XT, White FJ, Wolf ME (1997). Increased responsiveness of ventral tegmental area dopamine neurons to glutamate after repeated administration of cocaine or amphetamine is transient and selectively involves AMPA receptors. J Pharmacol Exp Ther 281: 699-706.

Zheng Y, Sudou K, Nawa H, Namba H (2006). Field potential recording in the ventral tegmental area: pharmacological and toxicological evaluations of postsynaptic dopaminergic neuron activity. Neurosci Res 55: 426-433. 